\title{
Branchotenthes octohamatus sp. n. (Monogenea: Hexabothriidae) from the gills of the southern fiddler ray, Trygonorrhina fasciata (Rhinobatidae) in South Australia: description of adult and larva
}

\author{
Vanessa Glennon ${ }^{1}$, Leslie A. Chisholm ${ }^{1}$ and Ian D. Whittington ${ }^{1,2}$ \\ ${ }^{1}$ Marine Parasitology Laboratory, School of Earth and Environmental Sciences, The University of Adelaide, North Terrace, \\ South Australia 5005, Australia; \\ ${ }^{2}$ Monogenean Research Laboratory, Parasitology Section, The South Australian Museum, North Terrace, South Australia 5000, \\ Australia
}

Key words: Monogenea, Polyopisthocotylea, Hexabothriidae, Branchotenthes, Trygonorrhina fasciata, Rhinobatidae, Australia

\begin{abstract}
Branchotenthes octohamatus sp. n. (Monogenea: Hexabothriidae) is described from the gills of the southern fiddler ray, Trygonorrhina fasciata Müller et Henle (Elasmobranchii: Rhinobatidae), off Adelaide, South Australia. It is distinguished from the type species, Branchotenthes robinoverstreeti Bullard et Dippenaar, 2003, by producing eggs that are joined end to end forming a chain, in the morphology of the male copulatory organ that has a pronounced constriction in duct diameter between proximal and distal regions, the possession of a thin muscular layer surrounding the proximal part of the male copulatory organ and distal region of the vaginae, and by the absence of a raised process on the shaft of the hamulus. An amended generic diagnosis is provided and the reliability of sperm duct number as a generic character is discussed. The oncomiracidium of $B$. octohamatus is also described and is the first monogenean to be described with only eight hooklets in the larval haptor. This discovery of eight hooklets may be important for higher-level monogenean evolutionary hypotheses.
\end{abstract}

The Hexabothriidae Price, 1942 includes polyopisthocotylean monogeneans exclusively parasitic on the gills of chondrichthyan fishes (the sharks, rays and chimaeras). Since the first hexabothriid was discovered by Kuhn (1829), over 60 species have been described from almost as many host species. Currently however, the taxonomy of the Hexabothriidae is in a state of confusion. Boeger and Kritsky (1989) have undertaken the only comprehensive familial revision. They recognized 13 genera but declared many species incertae sedis, suggesting these species as likely representatives of presently unrecognized genera. Recently, Bullard and Dippenaar (2003) proposed Branchotenthes to accommodate $B$. robinoverstreeti from the gills of the bowmouth guitarfish, Rhina ancylostoma Bloch et Schneider (Rhynchobatidae) in the Indian Ocean. A combination of characters was used to differentiate Branchotenthes from other hexabothriid genera but the possession of dilated, glandular-walled 'vasa efferentia' was considered the most distinct feature.

Selection of appropriate characters to determine species relationships is undoubtedly difficult for the Hexabothriidae. Studies of larval morphology have proven valuable in the clarification of taxonomic issues within some monogenean families (e.g. for Monocotylidae see Dawes and Griffiths 1958, 1959, Llewellyn 1959, Kearn 1970, Chisholm 1998), and may have value for the Hexabothriidae. Yet the larvae of only four hexabothriid species have so far been described: Erpocotyle catenu- lata (as Neoerpocotyle catenulata, see Euzet 1955); Hexabothrium appendiculatum (as H. canicula, see Euzet 1957, Whittington 1987); Epicotyle torpedinis (as Squalonchocotyle torpedinis, see Euzet 1957); Rajonchocotyle emarginata (see Llewellyn 1957, Wiskin 1970, Whittington 1987).

Recent examination of southern fiddler rays, Trygonorrhina fasciata Müller et Henle (Rhinobatidae) off Adelaide, South Australia, has revealed the gills to bear a new species of hexabothriid possessing two 'vasa efferentia' conforming closely to Branchotenthes. Subsequent capture and maintenance of additional live $T$. fasciata specimens in aquaria enabled collection of hexabothriid eggs for studies of larvae to provide further information about Branchotenthes.

\section{MATERIALS AND METHODS}

Seven southern fiddler rays (T. fasciata) were caught by hand in shallow water at Kingston Point, Seacliff, near Adelaide, South Australia between April and May, 2003. Rays were transported alive to The University of Adelaide (UA) and transferred to a 1,000-1 aquarium containing recirculating, aerated seawater. Ammonium and nitrite levels were monitored using Hagen ammonia $\left(0.0-6.1 \mathrm{mg} \mathrm{l}^{-1}\right)$ and nitrite $(0.0-$ $\left.3.3 \mathrm{mg}^{-1}\right)$ test kits for fresh and salt water. Aquarium water quality was maintained by replacing approximately half the tank volume, bi-weekly, with fresh seawater. One piece of plastic fly wire $(60 \times 50 \mathrm{~cm})$ was secured in the tank to trap monogenean eggs to promote a continuous and heavy infec- 
tion (see Ernst and Whittington 1996). Rays were fed daily on chopped pilchard.

To obtain adult hexabothriid specimens, two rays were killed by pithing. Each gill arch was excised, placed into glass Petri dishes containing fresh filtered seawater (FSW) filtered through Whatman qualitative paper and then examined for parasites using a stereodissecting microscope with incident light. Parasites were removed using fine forceps and a soft paint brush and transferred to dishes of clean FSW. Two specimens were lightly compressed in a drop of FSW beneath a coverslip and studied alive, using phase contrast and differential interference (Nomarski) microscopes. The presence and position of ducts and glands, which are often seen more easily in live material, was determined. Parasites were flattened and fixed in $10 \%$ formalin under a coverslip. Parasites were either left unstained or were stained in acetocarmine, dehydrated in a graded ethanol series, cleared in cedarwood oil and mounted on microscope slides in Canada balsam beneath a coverslip. A number of fixed specimens were mounted directly in Hoyer's mounting medium to reveal hooklets and other sclerites. Mounted specimens were examined using a compound microscope with phase contrast or Nomarski optics and drawings made with the aid of a drawing tube. Measurements were taken using a computerized digitizing system, similar to that described by Roff and Hopcroft (1986). Unless otherwise indicated, measurements are given in micrometres as the mean, with the range and sample size in parentheses.

Oncomiracidial anatomy was described by studying live larvae. Hexabothriid eggs were collected by isolating individual infected rays kept in the UA aquarium for periods of 2 to 5 $\mathrm{h}$ in a $60-1$ bin containing $\sim 401$ of FSW aerated by an air stone. Following isolation, rays were returned to the aquarium. The water in which each ray had been held was filtered through a $63-\mu \mathrm{m}$ Nitex mesh sieve and the residue examined in a Petri dish containing FSW for eggs laid by parasites in vivo. Eggs were transferred to glass crystallising dishes (volume approximately $30 \mathrm{ml}$ ) and incubated in a LD12:12 light regime (light on, 07:00 h; light off, 19:00 h) in a controlled light cabinet at ambient room temperature (average daily minima and maxima: 17 to $21^{\circ} \mathrm{C}$ ). The desired light regime was achieved by a programmed timer connected to a $7 \mathrm{~W}$ bulb covered with a blue Cinemoid filter inside the cabinet. The FSW for each batch was replaced daily. After hatching, individual larvae were transferred to a glass slide in a small drop of seawater, then lightly compressed beneath a coverslip. Each larva was viewed using phase contrast optics under oil immersion. Measurements of total larval length and width and pharynx length and width were made when larvae were lightly compressed. Hooklets were measured when larvae were fully flattened. Hooklet numbering follows Euzet and Raibaut (1960).

In this paper we propose the following terminology for hexabothriids: 'sperm ducts' in preference to 'vasa efferentia' and 'common sperm duct' in preference to 'vas deferens' to avoid confusion. This confusion arises because 'vasa efferentia' are defined as 'many convoluted ducts' (Lawrence 1992) but this is not the character being described.

Museums from which specimens were either borrowed or deposited are referred to in the text as follows: Institute of Parasitology, Academy of Sciences of the Czech Republic,
České Budějovice, Czech Republic (IPCR); South Australian Museum (SAMA), Australian Helminthological Collection (AHC), North Terrace, Adelaide, South Australia 5000, Australia; United States National Parasite Collection (USNPC), Beltsville, Maryland 20705, USA.

The following type material was studied for comparative purposes: Branchotenthes robinoverstreeti Bullard et Dippenaar, 2003, from Rhina ancylostoma, off Trafalgar coast, South Africa, USNPC No. 92533 (paratypes, 2 slides).

\section{RESULTS}

Hex a b othriida e Price, 1942

\section{Branchotenthes Bullard et Dippenaar, 2003}

Amended generic diagnosis. With characters of Hexabothriidae sensu Boeger and Kritsky (1989). Haptor symmetrical, with armed terminal appendix; haptor bearing three pairs of equal-sized suckers arranged consecutively along longitudinal axis; sucker sclerites of equal size, C-shaped, with point. Two sperm ducts dilated distally, with glandular wall, uniting medially to form common sperm duct. Male copulatory organ thickwalled, unarmed, with distinct proximal and distal regions; proximal region oblong; distal region elongate, tapering. Vaginae longitudinally parallel, with distinct proximal and distal regions; proximal region thinwalled, glandular, highly sinuous; distal region thick or thin-walled, musculoglandular. Ovary lobate proximally, with sinuous descending branch and straight ascending branch. Seminal receptacle thin-walled, median, occupying region between descending and ascending ovarian branches. Ootype smooth. Egg with two polar filaments, not connected to another egg (e.g. $B$. robinoverstreeti), or connected end to end forming chain (e.g. see new species described below). Gill parasites of rhynchobatids (sharkfin guitarfish) and rhinobatids (shovelnose rays).

\section{Branchotenthes octohamatus sp. n.}

Figs. 1-5

Description of adult. Based on 2 live and 11 whole mounted specimens. Body elongate, total length including haptor 6,627 $(2,548-10,528, \mathrm{n}=9)$. Maximum body width 1,384 $(670-2,364, \mathrm{n}=9)$ in region of testes (Fig. 1A). Haptor symmetrical (Fig. 1A) with three pairs of equal-sized armed suckers and terminal appendix; maximum haptor width 1,949 $(961-2,971, \mathrm{n}=9)$ at level of sucker pair two. Appendix 1,294 (490-2,051, n $=10)$ long, $819(297-1,206, \mathrm{n}=10)$ wide, bearing two terminal, unarmed suckers $386(150-530 \mathrm{n}=11)$ long, $180(66-297 \mathrm{n}=11)$ wide (Fig. 1A). Appendix length relative to total body length $0.18(0.14-0.30, \mathrm{n}=9)$. Single pair of hamuli (= anchors of Bullard and Dippenaar 2003) (Figs. 1A, B, 2A), 86 (75-96, n = 22) long, between unarmed suckers; one pair of hooklets between hamuli (Figs. 1A, C). One hooklet embedded in musculature of each sucker but extremely difficult to see in large specimens. Haptoral suckers 619 (264-859, 

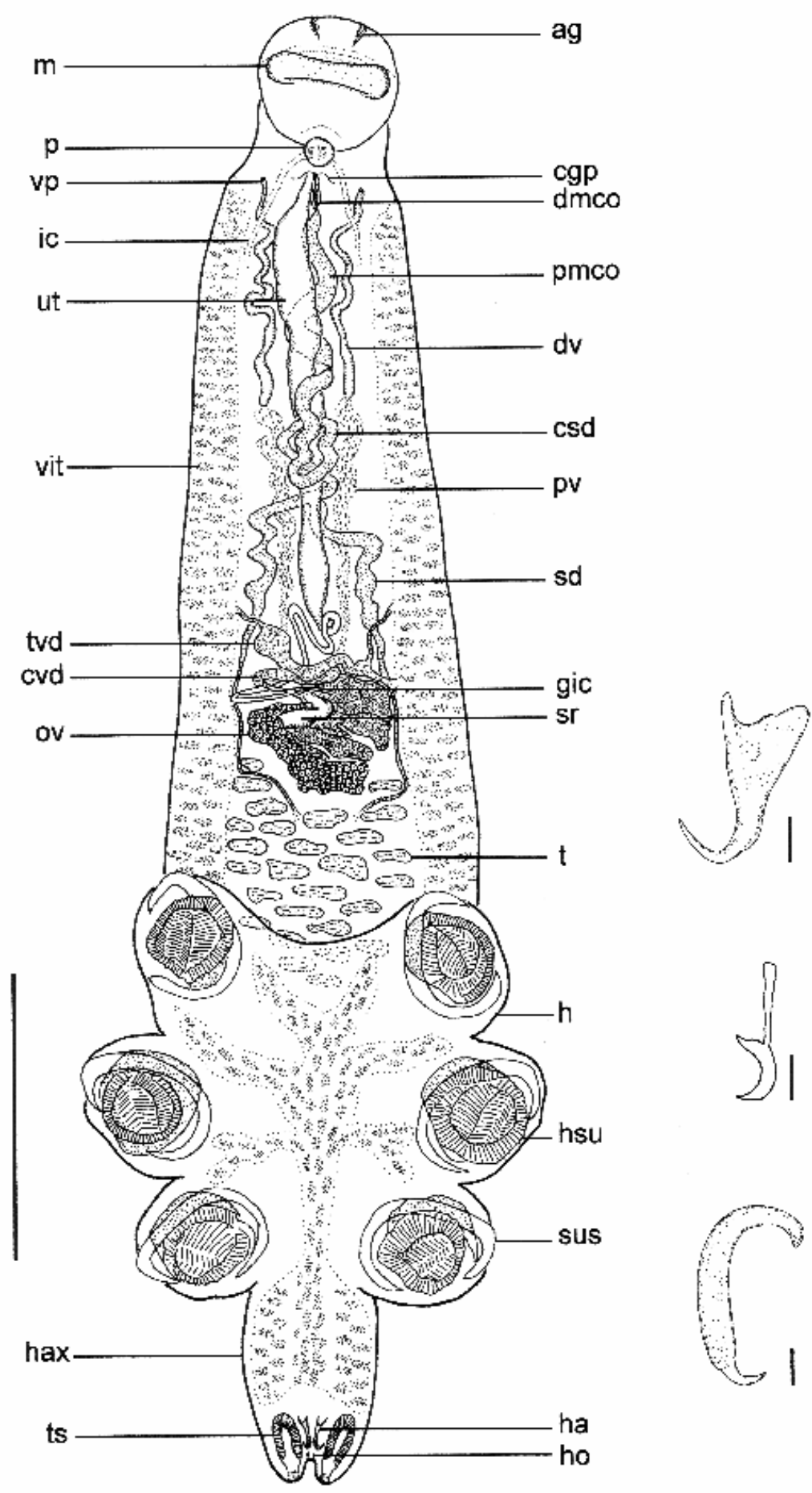

B
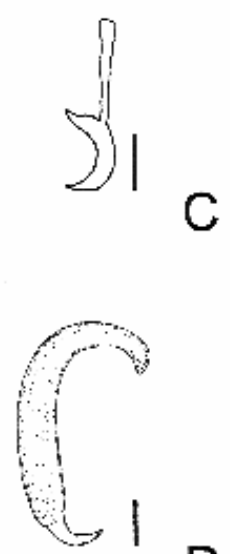

A

Fig. 1. Branchotenthes octohamatus sp. $\mathrm{n}$. A - Whole body composite drawing of adult, ventral view. B - Hamulus. C - Hooklet. D - Sucker sclerite. Abbreviations: ag - anterior gland duct opening; cgp - common genital pore; csd - common sperm duct; cvd - common vitelline duct; dmco - distal part of male copulatory organ; dv - distal region of vagina; gic - genito-intestinal canal; h - haptor; ha - hamulus; hax - haptoral appendix; ho - hooklet; hsu - haptoral sucker; ic - intestinal caecum; $\mathrm{m}$ - mouth; ov - ovary; p - pharynx; pmco - proximal part of male copulatory organ; pv - proximal region of vagina; sd - sperm duct; $\mathrm{sr}$ - seminal receptacle; sus - sucker sclerite; $\mathrm{t}$ - testis; ts - terminal unarmed sucker; tvd - transverse vitelline duct; ut - uterus; vit - vitelline follicle; vp - vaginal pore. Scale bars: $A=1,000 \mu \mathrm{m} ; \mathrm{B}=20 \mu \mathrm{m} ; \mathrm{C}=5 \mu \mathrm{m} ; \mathrm{D}=200 \mu \mathrm{m}$. 


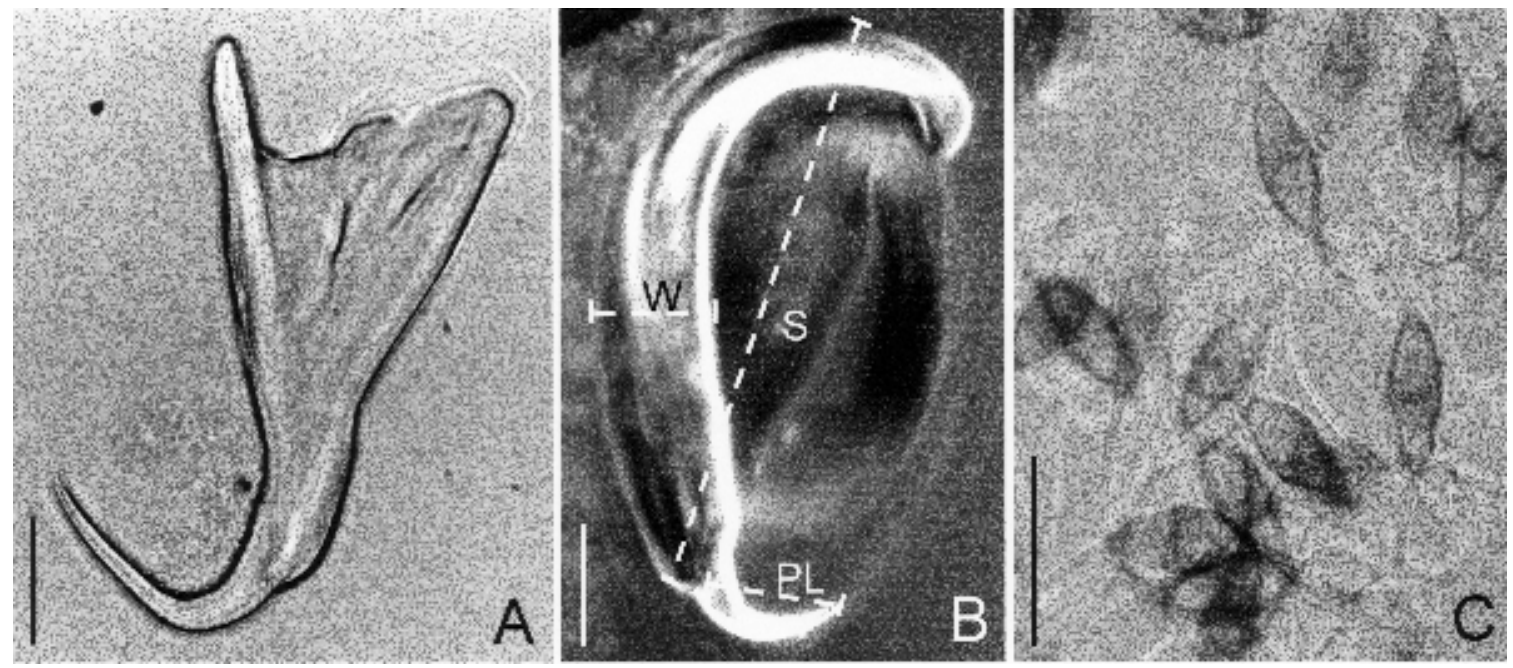

Fig. 2. Branchotenthes octohamatus sp. n. Phase contrast photomicrographs. A - Hamulus. B - Sucker sclerite. C - Egg chain. Abbreviations: PL - point length; $\mathrm{S}$ - shaft length; $\mathrm{W}$ - maximum width. Scale bars: $\mathrm{A}=20 \mu \mathrm{m} ; \mathrm{B}, \mathrm{C}=200 \mu \mathrm{m}$.

$\mathrm{n}=31$ ), internally ridged and striated (Fig. 1A). Sucker sclerite shaft length 1,039 $(533-1,461, \mathrm{n}=31)$ (Figs. 1A, D, 2B); point length $185(150-229, \mathrm{n}=10)$ (Figs. 1D, 2B); maximum width $102(84-144, \mathrm{n}=8)$ (Figs. 1D, 2B).

Mouth ventral, subterminal, $414(219-522, \mathrm{n}=9)$ wide (Fig. 1A). Two gland duct openings containing granular secretion visible at anterior extremity (Fig. 1A); glands and ducts leading to these openings not seen. Pharynx muscular, spherical $104(49-143, \mathrm{n}=9)$ in diameter. Oesophagus not seen. Intestinal caeca dendritic; branches extend laterally from each longitudinal caecum and travel length of worm; confluent posteriorly, distributed in haptor as illustrated (Fig. 1A).

Testicular mass post-ovarian, occupying final third of body proper (Fig. 1A). Number of testes not determined. Two sperm ducts, one on each side of body; run anteriorly in sinuous path before fusing at mid-line to form common sperm duct. Common sperm duct loops prior to constriction at junction with proximal region of male copulatory organ (Fig. 1A). Male copulatory organ comprising two distinct regions; proximal region oblong, muscular, dilated, dorsal to uterus, narrowing to thin tube at junction with distal male copulatory organ (Figs. 1A, 3A). Distal region unarmed, elongate (Fig. $3 \mathrm{~A}$ ); glandular region not seen. Common genital pore a transverse slit at midline immediately posterior to intestinal bifurcation (Fig. 1A).

Two longitudinally parallel vaginae; pores open ventrally, lateral to intestinal caeca, approximately level with common genital pore; comprise distinct proximal and distal regions (Fig. 1A). Distal region of vagina tube-like with thin muscular layer; proportion of distal region to total body length $0.14(0.10-0.16, \mathrm{n}=14)$; proximal region thin-walled, glandular (Fig. 1A). Ducts pass obliquely beneath gut caeca presumably joining transverse vitelline ducts but path unclear (Fig. 1A).
Ovary in centre of body, lobate proximally, with sinuous descending branch and straight ascending branch (Fig. 1A). Seminal receptacle thin-walled, occupies region between descending and ascending ovarian branches. Oviduct narrow; genito-intestinal canal runs dorsal to ovary on left; path unclear (Fig. 3B). Ootype smooth, elongate (Fig. 3B). Mehlis' glands present at base of ootype at junction with oviduct (Fig. 3B). Uterus dorsal to common vitelline duct; opens at common genital pore (Fig. 1A). Vitelline follicles occurring as dense lateral bands on each side of body, from level just posterior to vaginal pores extending into haptor. Transverse vitelline ducts meet medially to form common vitelline duct (Fig. 1A). Eggs fusiform 139 (135$141, \mathrm{n}=10)$ long, $68(64-73, \mathrm{n}=10)$ wide (Figs. 2C, $3 \mathrm{C})$; connected end to end via long filamentous appendage 630 (566-663, $\mathrm{n}=10$ ) (Fig. 2C); maximum recorded chain length $92 \mathrm{~mm}$ comprising 122 eggs.

Description of larva. Based on 10 live oncomiracidia. Larva $170(147-201, \mathrm{n}=10)$ long, $88(61-112, \mathrm{n}=$ 10) wide (Figs. 4, 5A). Locomotory cilia absent, but sensory sensilla distributed symmetrically around head region (Figs. 4, 5B); anteriormost sensilla evenly spaced; anterolateral sensilla clumped. Refringent droplets, likely lipid, dispersed throughout body (Figs. 4, 5A, B). Pigmented eyespots absent. Pharynx 30 (25-35, $\mathrm{n}=10)$ long, $31(25-35, \mathrm{n}=10)$ wide. Mouth ventral, subterminal. Conspicuous mass of refringent droplets (likely rudimentary gut) immediately posterior to pharynx (Figs. 4, 5A, B).

Two anteromedian glands containing granular secretion open at anterior end (Fig. 4). Remainder of anterior gland system unclear; four duct endings (two on each side of head) containing needle-like secretion, two additional duct endings containing granular secretion between anteromedian gland duct openings (Fig. 4); these duct endings could not be traced to origin. 


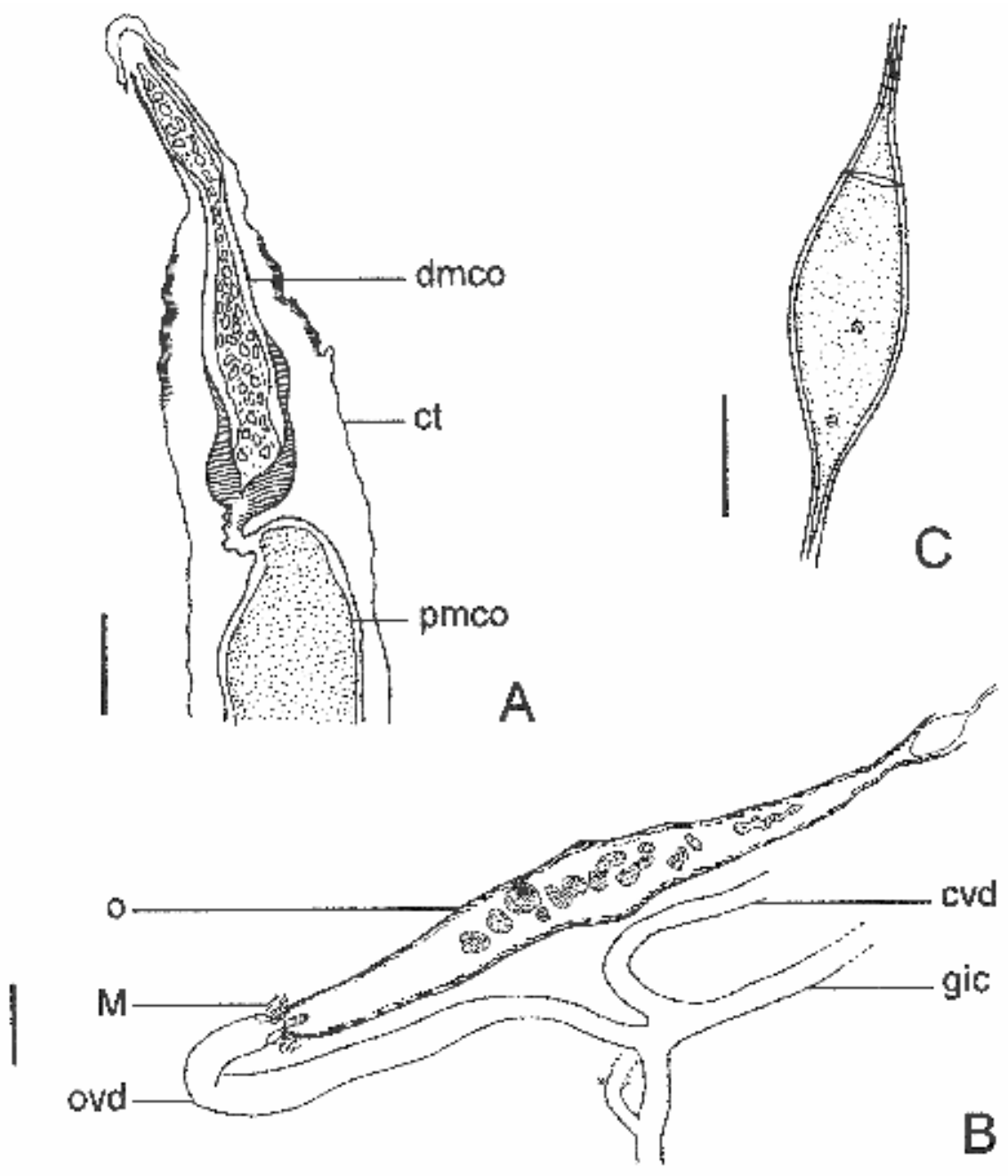

Fig. 3. Branchotenthes octohamatus sp. n. A - Male copulatory organ, ventral view, showing constriction of proximal region (pmco) at junction with distal region (dmco). B - Ducts of the female reproductive system leading to ootype. C - Single egg. Abbreviations: ct - connective tissue; cvd - common vitelline duct; gic - genito-intestinal canal; $\mathrm{M}$ - Mehlis' glands; o - ootype; ovd - oviduct. Scale bars $=50 \mu \mathrm{m}$.

One prominent pair of flame bulbs anterior to pharynx (Figs. 4, 5B); no others observed. Path of ducts connecting flame bulbs not visible. Excretory bladders not seen.

Haptor with eight hooklets of similar shape and size, $14(12-16, \mathrm{n}=20)$ long, each with domus (Fig. 4). No hamuli observed in freshly hatched larvae.

Remarks. This is the first time a monogenean larva has been described with only eight hooklets. The larvae of the four other hexabothriid species described thus far have 10 hooklets. The hooklets of B. octohamatus persist as the haptor develops, although they are extremely difficult to see in adult specimens.

The single pair of flame bulbs observed in B. octohamatus larvae contrasts with four pairs described by Whittington (1987) for the ciliated larvae of both $R a j$ onchocotyle emarginata and Hexabothrium appendiculatum. Similarly, Euzet (1955) commented on the com- plicated nephridial system of the ciliated larva of Erpocotyle catenulata (as Neoerpocotyle catenulata), although the number and arrangement of flame bulbs was not specified. However, no mention of flame bulbs was made by Euzet (1957) in his description of the only other unciliated hexabothriid larva so far described: Epicotyle torpedinis (as Squalonchocotyle torpedinis). While it is possible that more flame bulbs may be present in the larva of B. octohamatus, the prominence and constancy of the single pair that was observed among the larvae examined, suggests this may be an additional, distinguishing feature of the larva of this species.

$\mathrm{T}$ y $\mathrm{p}$ e $\mathrm{h}$ o s $\mathrm{t}$ : Trygonorrhina fasciata Müller et Henle (Rhinobatidae).

$\mathrm{T}$ y $\mathrm{p}$ e 1 o c a 1 i t y : Kingston Point, Seacliff

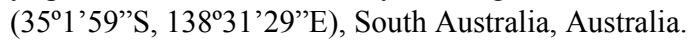

$\mathrm{S}$ i t e : Predominantly found on outer edge of primary gill lamella. 


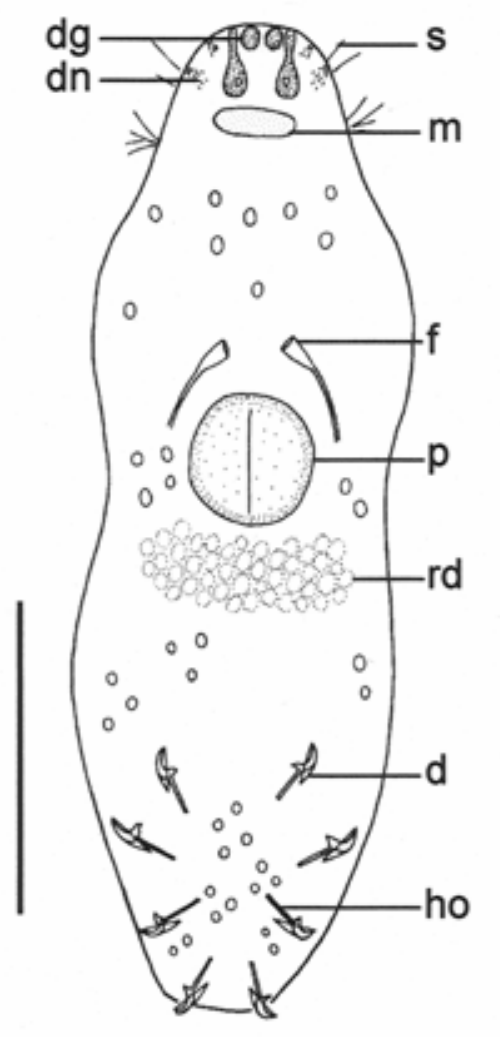

Fig. 4. Branchotenthes octohamatus sp. n. Oncomiracidium, whole body, ventral view. Abbreviations: $d$ - domus; $d g-$ duct-ending containing granular secretion; dn - duct-ending containing needle-like secretion; $\mathrm{f}$ - flame bulb; ho - hooklet; $\mathrm{m}$ - mouth; $\mathrm{p}$ - pharynx; rd - refringent droplet; $\mathrm{s}$ - sensory sensilla. Scale bar $=50 \mu \mathrm{m}$.

$\mathrm{P} \mathrm{r}$ e $\mathrm{v}$ a 1 e $\mathrm{n} \mathrm{c}$ e $\mathrm{d}$ a $\mathrm{t}$ a : Three of seven rays (43\%) were infected by mature hexabothriids at the time of capture.

T y p e m a t e r i a 1 : Holotype SAMA AHC 28766; 6 paratypes SAMA AHC 28767-72; 2 paratypes IPCR M412; 2 paratypes USNPC No. 095759.00.

E $t$ y $\mathrm{m}$ o 1 o g y: The species name (Latin) refers to the eight (octo) hooklets (hamatus) found in the larval haptor.

\section{DISCUSSION}

The new hexabothriid species described here conforms closely to the generic diagnosis for Branchotenthes but several amendments were required to accommodate it fully. The most significant revision concerns egg morphology. Although both Branchotenthes species produce eggs with two polar filaments, the eggs of the type species, $B$. robinoverstreeti were reported to be unconnected to other eggs (see Bullard and Dippenaar 2003), whereas the eggs of B. octohamatus are clearly joined end to end to form a chain. Boeger and Kritsky (1989) also noted a similar 'either/or' state for eggs of Erpocotyle species in their generic revision. However, during this study, we observed that the adults of $B . o c$ tohamatus we removed from a host and placed in a Petri dish containing FSW produced eggs that were not connected to other eggs and were often irregularly shaped, lacking vitelline cells. We attributed this anomaly in egg morphology of B. octohamatus to stress experienced by the worms following their detachment from the host. Since specimens used to describe $B$. robinoverstreet came from a host that had died in a gill net (Bullard and Dippenaar 2003), it seems likely that these eggs may also have been the product of stressed worms and may not truly represent the eggs produced by the type species under normal conditions on the host.

In addition to the difference in egg morphology, $B$. octohamatus is distinguished from $B$. robinoverstreeti by the morphology of the male copulatory organ, the common sperm duct, the distal region of the vaginae and the hamuli. In B. octohamatus, a pronounced constriction divides the male copulatory organ into distinct proximal and distal regions (Figs. 1A, 3A). These regions are characters of Branchotenthes as stated by Bullard and Dippenaar (2003). Yet we were unable to find similar distinction between proximal and distal regions in the male copulatory organ of type material of $B$. robinoverstreeti. We did, however, observe a slight deviation in the path of the male copulatory organ towards the anterior of the worm (see figs. 10 and 11 of Bullard and Dippenaar 2003), although this seemed to be the result of a slight fold in the tegument, rather than differentiation of the organ itself. The muscular wall of the proximal part of the male copulatory organ and the muscle layer surrounding the distal region of the vaginae are both much thinner in $B$. octohamatus than in $B$. robinoverstreeti. Furthermore, the common sperm duct appears proportionally longer in B. octohamatus. A single, raised process visible on the shaft of each hamulus in B. robinoverstreeti (see fig. 16 in Bullard and Dippenaar 2003) is absent from the hamuli of B. octohamatus (Figs. 1B, 2A).

The presence of two sperm ducts (= vasa efferentia), as opposed to a single vas deferens, was considered by Bullard and Dippenaar (2003) to be a defining character for Branchotenthes. However, this is not a character unique to Branchotenthes. Indeed, six hexabothriid species, two of them type species, from four genera (Erpocotyle, Hexabothrium, Protocotyle and Squalonchocotyle) have also been reported with two sperm ducts. It might be expected that such a distinctive morphological feature should be consistent between closely related species, however, the possession of this feature is not consistent among species in these genera (Maillard 1970, Euzet and Maillard 1974, Euzet, pers. comm.). For example Squalonchocotyle centrophori has two sperm ducts, whereas Squalonchocotyle cerfontaini has only a single sperm duct (Maillard 1970). Although clearly important and highly distinctive, the reliability of this character for generic diagnoses may presently be questionable, given current taxonomic uncertainties within the family. 

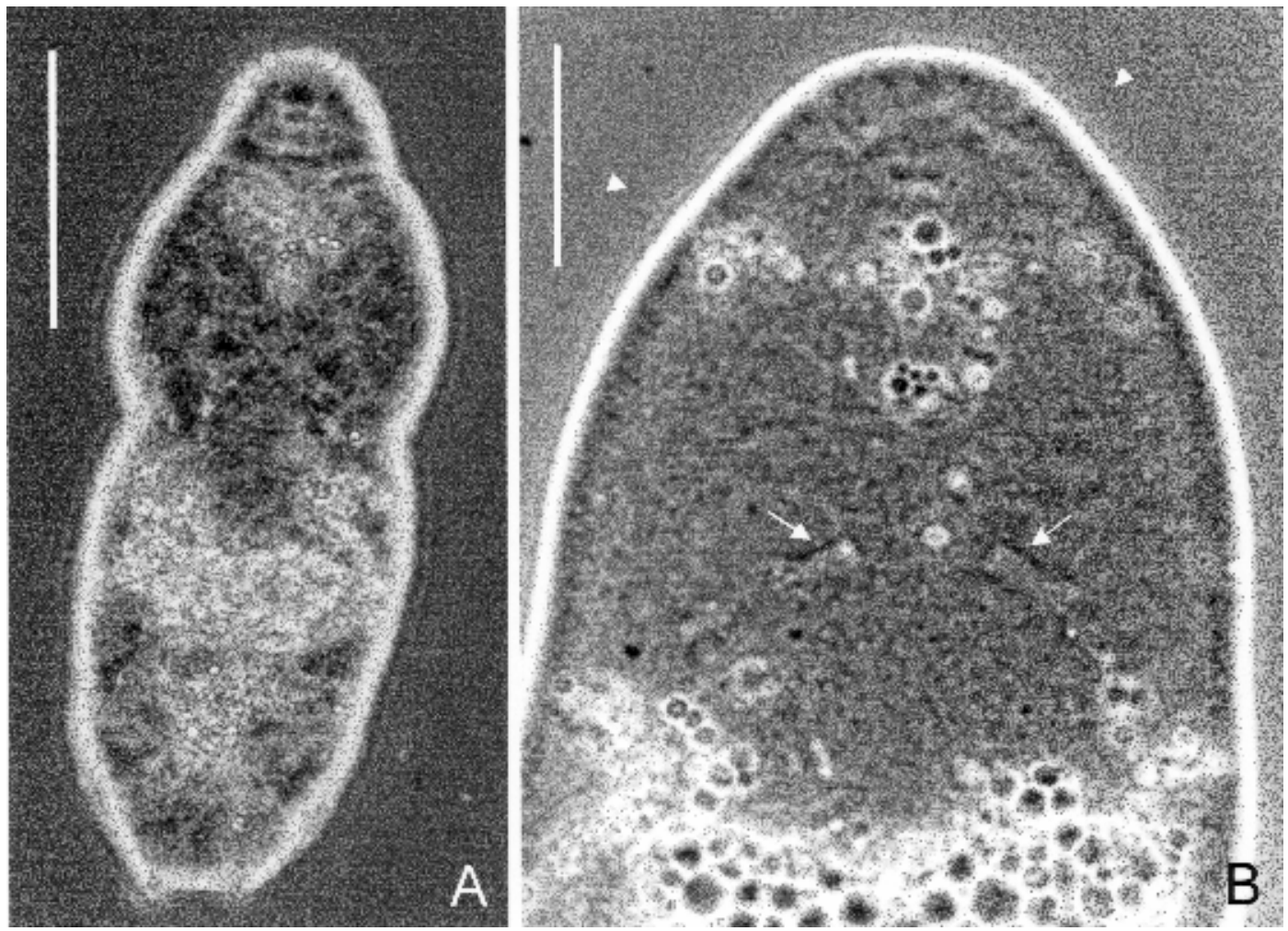

Fig. 5. Branchotenthes octohamatus sp. n. Oncomiracidium, phase contrast photomicrographs. A - Whole body, ventral view. B - Anterior end, ventral view. Note flame bulbs (arrows), sensory sensilla (arrowheads) and large refringent mass at the bottom of the photograph. Scale bars: $A=50 \mu \mathrm{m} ; \mathrm{B}=20 \mu \mathrm{m}$.

Although omitted from their diagnosis for Branchotenthes, Bullard and Dippenaar (2003) commented on the arrangement of cells lining the inner wall of the ootype. Specifically, they noted the cells were not arranged in distinctive longitudinal rows. Euzet and Maillard (1974) were the first to use the presence of longitudinal rows of cells lining the ootype as a character for hexabothriids and recognized two states for the ootype: rough (with longitudinal rows of cells) or smooth. Similarly, Boeger and Kritsky (1989) included this character in their revision of the Hexabothriidae. Branchotenthes octohamatus also lacks distinctive longitudinal rows of cells lining the ootype. In accordance with the terminology of Euzet and Maillard (1974) and Boeger and Kritsky (1989), the ootype of Branchotenthes may be described as smooth and this feature is added to the generic diagnosis. The presence and position of the seminal receptacle and the conformation of the ovarian branches that are important for generic diagnoses within the Hexabothriidae, are also added.

In discussions concerning the evolution of the Monogenea, the haptor and the composition and arrangement of sclerites occupies a central position (Llewellyn 1970, Malmberg 1986). Most evolutionary hypotheses are based on the assumption that a reduction in the number of haptoral hooklets has occurred from the ancestral state, widely thought to be 16 (Bychowsky 1957, Lle- wellyn 1970, Boeger and Kritsky 1993). However, Malmberg $(1986,1990)$ expressed an alternative view, suggesting progressive rather than regressive evolution in the number of haptoral hooklets. Irrespective of viewpoint, hooklet number and arrangement is an important character in monogenean classification and systematics. Branchotenthes octohamatus is the first monogenean species to be described with only eight hooklets in the larva. All other hexabothriid larvae described possess 10 hooklets (Euzet 1955, 1957, Llewellyn 1957, Wiskin 1970, Whittington 1987). Euzet and Raibaut (1960) distinguished a posterolateral pair of hooklets (unnumbered) and four lateral pairs numbered L1 to L4 from posterior to anterior, in their fig. 1 in a study of post-larval development in the hexabothriid Epicotyle torpedinis (as Squalonchocotyle torpedinis) which infects the marbled electric ray, Torpedo marmorata Risso. The discovery of eight hooklets in the larva of $B$. octohamatus provides evidence of an additional form in the evolution of this character. Further study of larval hexabothriids is necessary to determine whether other genera share this character. This evolutionary 'link' may be useful in the future to help resolve problematic relationships within the Hexabothriidae, as well as offering insight into more general hypotheses about relationships within the Monogenea. 
Acknowledgements. We thank Eric Hoberg and Pat Pilitt (USNPC) for the loan of specimens. We are especially grateful to Delane Kritsky (Idaho State University) for examining specimens and offering valuable guidance. We also thank Ian Beveridge (University of Melbourne) for his expertise in Latin nomenclature. Funding for this research was provided by the
School of Earth and Environmental Sciences of the University of Adelaide to V. Glennon during her Honours (2003) and Ph.D. (2004 onwards) candidature and Australian Research Council grant nos. A00104437 (2001-2003) and DP0557697 (2005-2007) awarded to IDW.

genea, Hexabothriidae). Bull. Soc. Neuchâtel Sci. Nat. 83: 101-108.

KEARN G.C. 1970: The oncomiracidia of the monocotylid monogeneans Dictyocotyle coeliaca and Calicotyle kroyeri. Parasitology 61: 153-160.

KUHN J. 1829: Description d'un nouvel epizoaire du genre Polystoma qui se trouve sur les branchies de la petite roussette (Squalus catulus) suivie de quelques observations sur le Distoma megastomum et le Cysticercus leporis variabilis de Bremser. Ann. Sci. Obs. Paris 2: 450-465.

LAWRENCE E. 1992: Henderson's Dictionary of Biological Terms. Tenth Edition. Longman Scientific and Technical, Essex, 645 pp.

LLEWELLYN J. 1957: The larvae of some monogenetic trematode parasites of Plymouth fishes. J. Mar. Biol. Assoc. U.K. 36: 243-259.

LLEWELLYN J. 1959: Relationship between Dictyocotyle and Calicotyle. Nature 183: 835-836.

LLEWELLYN J. 1970: Monogenea. In 'Technical review: Taxonomy, genetics and evolution of parasites.' Second International Congress of Parasitology. J. Parasitol. 56: 493-504.

MAILLARD C. 1970: Trois nouvelles espèces d'Hexabothriidae (Monogenea) parasites de Selaciens du golfe du Lion. Ann. Parasitol. Hum. Comp. 45: 563-576.

MALMBERG G. 1986: The major parasitic platyhelminth classes - progressive or regressive evolution. Hydrobiologia 132: 23-29.

MALMBERG G. 1990: On the ontogeny of the haptor and the evolution of the Monogenea. Syst. Parasitol. 17: 1-65.

ROFF J.C., HOPCROFT R.R. 1986: High precision microcomputer based measuring system for ecological research. Can. J. Fish. Aquat. Sci. 43: 2044-2048.

WHITTINGTON I.D. 1987: A comparative study of the anatomy of the oncomiracidia of the hexabothriid monogeneans Rajonchocotyle emarginata and Hexabothrium appendiculatum. J. Mar. Biol. Assoc. U.K. 67: 757-772.

WISKIN M. 1970: The oncomiracidium and post-oncomiracidial development of the hexabothriid monogenean Rajonchocotyle emarginata. Parasitology 60: 457-479. 